\title{
Endoscopic suturing for refractory bilious reflux after gastroduodenostomy and gastrojejunostomy
}

A 35-year-old woman who had undergone previous multiple abdominal surgeries, including Billroth I gastrectomy with gastrojejunostomy and gastroduodenostomy, presented with a 6-month history of regurgitation and bilious vomiting. These symptoms were refractory to proton pump inhibitors, prokinetics, and lifestyle modification. Contrast study ( $\triangleright$ Fig. $\mathbf{1}$ a) revealed a patent gastrojejunostomy with flow of contrast into the duodenal loop and no distal obstruction. Endoscopy revealed significant bilious secretions in the stomach with a patent gastrojejunostomy and gastroduodenostomy.

To close the gastroduodenostomy stoma, we first applied argon plasma coagulation to the margins to promote subsequent cicatrization. We then approximated the margins of the wall defect by placing two layers of sutures using the Overstitch Endoscopic Suturing System (Apollo Endosurgery, Austin, Texas, USA) as shown in - Video 1 . A post-procedure contrast study showed no contrast flow across the gastroduodenostomy stoma ( $>$ Fig. 1 b).

The management of high volume bilious reflux is challenging in cases refractory to lifestyle modification and medications [1]. Gastroduodenostomy increases the risk of bilious reflux, dumping syndrome, and malabsorption. The management of gastroduodenostomy-related refractory bile reflux consists of surgical therapies such as dismantling the gastroduodenostomy and creation of a jejuno-jejunostomy. In this case, we used an endoscopic suturing device to close the stoma to alleviate the symptoms related to bilious reflux. A large multicenter experience with endoscopic suturing for gastrointestinal defects showed $97.5 \%$ technical success and $78.9 \%$ achieved long term clinical success [2]. Although clinical success for anastomotic leak closure was only $27 \%$, it was $93 \%$ for perforation and $80 \%$ for fistula [2]. The long term
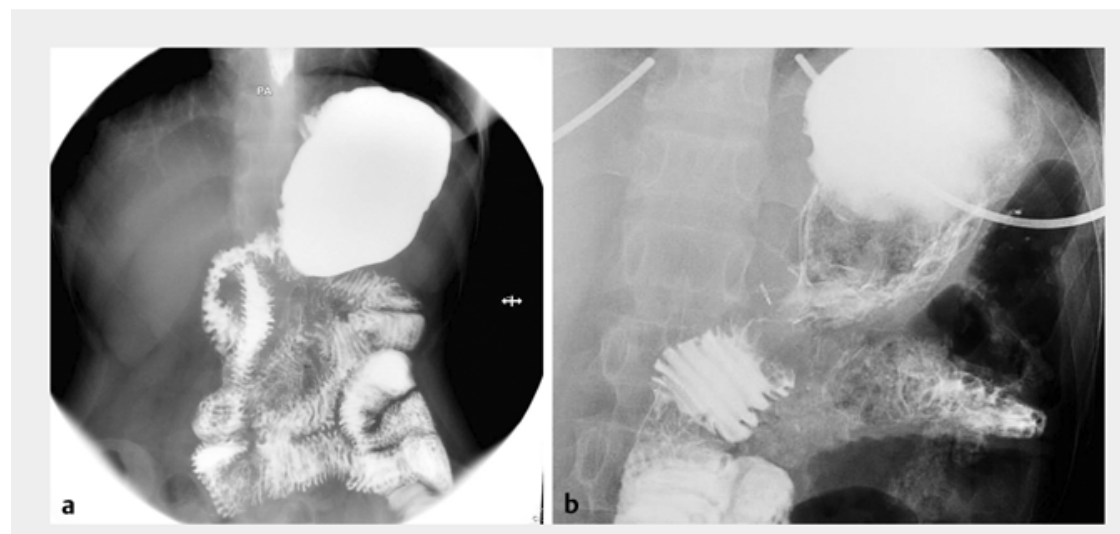

- Fig. 1 Barium contrast studies. a Preprocedure, showing gastroduodenostomy and gastrojejunostomy. b Post-procedure, showing no flow across the gastroduodenostomy.

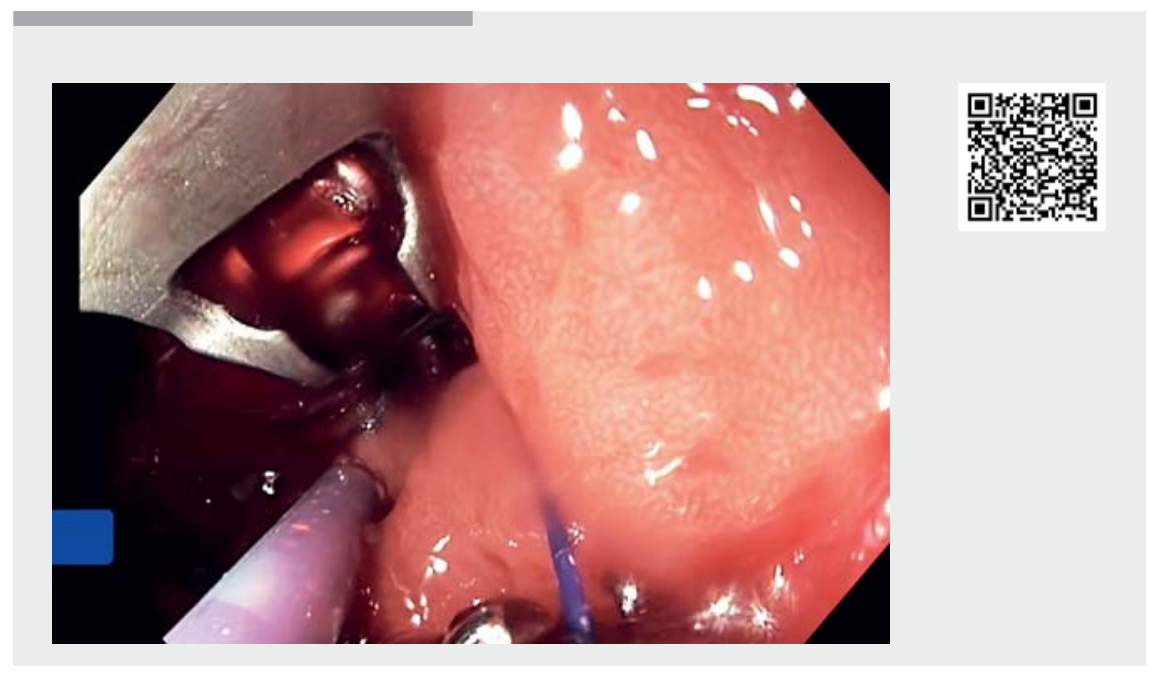

Video 1 Endoscopic suturing of gastroduodenostomy.

success can be achieved with endoscopic suturing, thereby circumventing the need for surgery $[3,4]$.

Endoscopy_UCTN_Code_CPL_1AN_2AG

\section{Competing interests}

None
The authors

Nitin Jagtap ${ }^{1}$, Rakesh Kalapala', G. Venkat Rao $^{2}$, D. Nageshwar Reddy ${ }^{1}$

1 Department of Medical Gastroenterology, Asian Institute of Gastroenterology, Hyderabad, India

2 Department of Surgical Gastroenterology, Asian Institute of Gastroenterology, Hyderabad, India 


\section{Corresponding author}

\section{Nitin Jagtap, MD, DNB}

Department of Medical Gastroenterology, Asian Institute of Gastroenterology, 6-3-661 Somajiguda, Hyderabad 500-082, India Fax: +91-40-23324255

docnits13@gmail.com

\section{References}

[1] Sifrim D. Management of bile reflux. Gastroenterol Hepatol (N Y) 2013; 9: 179-180

[2] Sharaiha RZ, Kumta NA, DeFilippis EM et al. A large multicenter experience with endoscopic suturing for management of gastrointestinal defects and stent anchorage in 122 patients: a retrospective review. J Clin Gastroenterol 2016; 50: 388-392
[3] Takeshita N, Ho KY. Endoscopic closure for full-thickness gastrointestinal defects: available applications and emerging innovations. Clin Endosc 2016; 49: 438-443

[4] Mukewar S, Kumar N, Catalano M et al. Safety and efficacy of fistula closure by endoscopic suturing: a multi-center study. Endoscopy 2016; 48: 1023-1028

\section{Bibliography}

DOI https://doi.org/10.1055/a-1063-6251

Published online: 9.12.2019

Endoscopy 2020; 52: E185-E186

(c) Georg Thieme Verlag KG

Stuttgart · New York

ISSN 0013-726X

\section{ENDOSCOPY E-VIDEOS}

https://eref.thieme.de/e-videos

回的回 Endoscopy E-Videos is a free access online section, reporting 国: on interesting cases and new techniques in gastroenterological endoscopy. All papers include a high quality video and all contributions are freely accessible online.

This section has its own submission website at

https://mc.manuscriptcentral.com/e-videos 